\title{
Notch2 Transduction by Feline Leukemia Virus in a Naturally Infected Cat
}

\author{
Shinya WATANABE ${ }^{1)}$, Jumpei ITO2), Takuya BABA ${ }^{2)}$, Takahiro HIRATSUKA ${ }^{2)}$, Kyohei KUSE'), Haruyo OCHI'), \\ Yukari $\mathrm{ANAI}^{2)}$, Masaharu HISASUE ${ }^{3)}$, Hajime TSUJIMOTO ${ }^{4)}$ and Kazuo NISHIGAKI ${ }^{1,2) *}$ \\ ${ }^{1)}$ Laboratory of Molecular Immunology and Infectious Disease, United Graduate School of Veterinary Science, Yamaguchi University, \\ 1677-1 Yoshida, Yamaguchi 753-8515, Japan \\ ${ }^{2)}$ Laboratory of Molecular Immunology and Infectious Disease, Joint Faculty of Veterinary Medicine, Yamaguchi University, 1677-1 \\ Yoshida, Yamaguchi 753-8515, Japan \\ ${ }^{3)}$ Laboratory of Veterinary Internal Medicine II, School of Veterinary Medicine, Azabu University, 1-17-71 Fuchinobe, Chuo-ku, \\ Sagamihara-shi, Kanagawa 252-5201, Japan \\ 4) Department of Veterinary Internal Medicine, Graduate School of Agricultural and Life Sciences, The University of Tokyo, 1-1-1 Yayoi, \\ Bunkyo-ku, Tokyo 113-8657, Japan
}

(Received 3 July 2013/Accepted 25 November 2013/Published online in J-STAGE 9 December 2013)

abSTRACT. Feline leukemia virus (FeLV) induces neoplastic and nonneoplastic diseases in cats. The transduction of cellular genes by FeLV is sometimes observed and associated with neoplastic diseases including lymphoma and sarcoma. Here, we report the first natural case of feline Notch 2 transduction by FeLV in an infected cat with multicentric lymphoma and hypercalcemia. We cloned recombinant FeLVs harboring Notch 2 in the env gene. Notch 2 was able to activate expression of a reporter gene, similar to what was previously reported in cats with experimental FeLV-induced thymic lymphoma. Our findings suggest that the transduction of Notch2 strongly correlates with FeLVinduced lymphoma.

KEY WORDS: feline leukemia virus, hypercalcemia, lymphoma, Notch2, transduction.

doi: 10.1292/jvms.13-0344; J. Vet. Med. Sci. 76(4): 553-557, 2014

Feline leukemia virus (FeLV), a gammaretrovirus that can cause a variety of both proliferative and degenerative diseases, is a major pathogen of feline lymphoma $[4,6]$. The transduction and activation of cellular proto-oncogenes by FeLV are mechanisms associated with the occurrence of lymphomas and sarcomas. Some recombinant FeLVs harboring cellular sequences, such as the transcription factor myc $[3,5,10,16,18-20,26]$ and T-cell receptor $\beta$ chain gene tcr [10], have been cloned from cats with naturally occurring lymphoma. FeLV, which transduces the intracellular region of Notch2, has been cloned from cats with experimental FeLV-induced thymic lymphoma [24].

Notch2 is a single-spanning transmembrane receptor that belongs to the Notch family of proteins, which play a role in cell differentiation and generation of tumors. The physical contact between cells expressing Notch ligands (e.g., deltalike ligands DLL1, 3 and 4 and Jagged1 and 2) and cells expressing the Notch protein induces proteolytic cleavage of Notch. This leads to release of the intracellular region of Notch into the nucleus, resulting in activation of responsive gene expression [reviewed in 11]. The active forms of Notch receptors have been reported in human patients with lymphoma and leukemia $[8,15,27,30]$. Here, we report, for the

*Correspondence to: Nishigaki, K., Laboratory of Molecular Immunology and Infectious Disease, Joint Faculty of Veterinary Medicine, Yamaguchi University, 1677-1 Yoshida, Yamaguchi 753-8515, Japan. e-mail: kaz@yamaguchi-u.ac.jp

(C2014 The Japanese Society of Veterinary Science

This is an open-access article distributed under the terms of the Creative Commons Attribution Non-Commercial No Derivatives (by-nc-nd) License $<$ http://creativecommons.org/licenses/by-nc-nd/3.0/>. first time, transduction of feline Notch2 sequence by FeLV (Notch2-FeLV) in a naturally infected cat with multicentric lymphoma and hypercalcemia.

A 2-year-old, 2.0-kg, spayed female Japanese domestic cat was referred to the Veterinary Medical Center, The University of Tokyo, in 1995 with consecutive debilitation, dehydration and leanness. The cat was tested positive for FeLV p27-Gag antigen and diagnosed with multicentric lymphoma. Although the tumor had temporally gone into remission after chemotherapy, relapse occurred, and severe hypercalcemia was observed in its blood biochemistry profile (Table 1). Radiography showed extensive calcification in the pulmonary field and concurrent decalcification in the scapula and humerus. Despite treatment with furosemide, infusion of sodium chloride saline, porcine calcitonin (4 IU/ $\mathrm{kg}$ ) and salmon calcitonin (4 IU/kg) for hypercalcemia, little effective palliation was observed, and the cat died with neural manifestations on day 21. Marked invasion of the tumor cells was seen in the multiple tissues at necropsy.

We extracted DNA from the tumor tissue and amplified the entire env gene of the FeLV provirus using two PCRs as described previously and employing specific primer pairs (5'-CAT CGA GAT GGA AGG TCC AAC G-3' (Fe-8S) and 5'-CAT GGT YGG TCY GGA TCG TAT TG-3'(Fe-3R) and 5'-GAG ACC TCT AGC GGC GGC CTA C-3' (Fe-9S) and 5'-GTC AAC TGG GGA GCC TGG AGA C-3' (Fe-7R)) [28]. Amplicons were cloned using Zero Blunt PCR Cloning Kit (Invitrogen, Carlsbad, CA, U.S.A.). Two FeLV clones (KeyN2-1 and KeyN2-2) contained feline Notch2-like sequences; the nucleotide sequences of the clones were deposited in GenBank under accession numbers AB818695 and AB818696, respectively (Fig. 1). Both sequences contained 
Table 1. Blood tests for the cat with lymphoma

\begin{tabular}{|c|c|c|c|c|c|}
\hline \multicolumn{3}{|c|}{ Complete blood count } & \multicolumn{3}{|c|}{ Blood biochemistry profile } \\
\hline & Patient & Reference range & & Patient & Reference range \\
\hline $\mathrm{RBC}\left(\times 10^{6} / \mu l\right)$ & 6.59 & $5.00-10.00$ & $\mathrm{BUN}(\mathrm{mg} / \mathrm{d} l)$ & 45.0 & $17.6-32.8$ \\
\hline Ht (\%) & 28 & $24-45$ & Cre $(\mathrm{mg} / \mathrm{d} l)$ & 1.8 & $0.8-2.4$ \\
\hline $\mathrm{Hb}(\mathrm{g} / \mathrm{d} l)$ & 9.5 & $8.0-15.0$ & $\operatorname{ALT}(\mathrm{U} / l)$ & 199 & $12-130$ \\
\hline $\mathrm{TP}(\mathrm{g} / \mathrm{d} l)$ & 6.8 & $5.7-7.8$ & $\operatorname{ALP}(\mathrm{U} / l)$ & 1 & $14-111$ \\
\hline $\operatorname{PLT}\left(\times 10^{3} / \mu l\right)$ & 95 & $300-800$ & $\mathrm{LDH}(\mathrm{U} / l)$ & 711 & $0-798$ \\
\hline $\mathrm{WBC}\left(\times 10^{3} / \mu l\right)$ & 15.8 & $4.9-20.0$ & $\mathrm{Ca}(\mathrm{mg} / \mathrm{d} l)$ & 17.3 & $8.8-11.9$ \\
\hline Eos $(\%)$ & 1 & $2-10$ & $\mathrm{P}(\mathrm{mmol} / l)$ & 8.0 & $2.6-6.0$ \\
\hline Band (\%) & 0 & $0-2$ & $\mathrm{Na}(\mathrm{mmol} / l)$ & 148 & $147-156$ \\
\hline Seg $(\%)$ & 72 & $35-75$ & $\mathrm{~K}(\mathrm{mmol} / l)$ & 4.2 & $3.4-4.6$ \\
\hline Lym (\%) & 26 & $20-55$ & $\mathrm{Cl}(\mathrm{mmol} / l)$ & 115 & $107-120$ \\
\hline Mono (\%) & 1 & $1-4$ & & & \\
\hline
\end{tabular}

ALP, alkaline phosphatase; ALT, alanine aminotransferase; Band, banded neutrophil; BUN, blood urea nitrogen; $\mathrm{Ca}$, calcium concentration; $\mathrm{Cl}$, chloride; Cre, creatinine; Eos, eosinophil; $\mathrm{RBC}$, red blood cells; $\mathrm{Ht}$, hematocrit; $\mathrm{Hb}$, hemoglobin; $\mathrm{K}$, potassium; $\mathrm{LDH}$, lactate dehydrogenase; Lym, lymphocyte; Mono, monocyte; Na, sodium; P, phosphate; PLT, platelet; Seg, segmented neutrophil; TP, total protein; WBC, white blood cells.

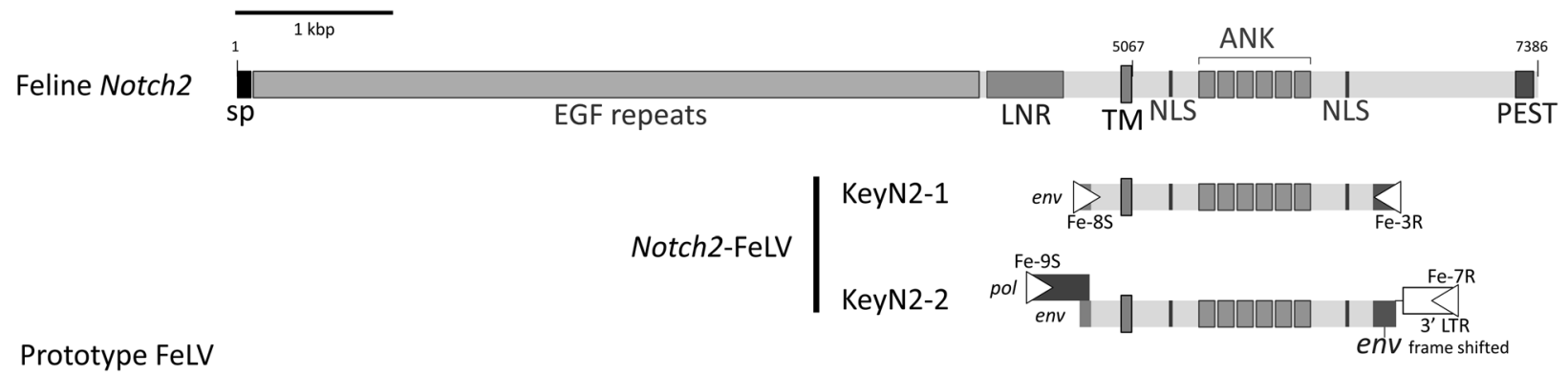

Prototype FelV

Fig. 1. Genetic structures of Notch2-FeLV. Schematic structures of the two clones of Notch2-FeLV (KeyN2-1 and KeyN2-2), feline Notch2 and prototype FeLV provirus. Notch2 contains EGF (blue) and Lin-12-Notch repeats (LNR; pink) in its extracellular region and ANK repeats (orange), two NLSs (green) and proline/glutamic acid/serine/threonine-rich motifs (PEST; purple) in its intracellular region. TM; Notch2 transmembrane. Triangle indicates the primers used for cloning the two Notch2-FeLVs. sp, signal peptide.

the same recombinant junctions, along with $5^{\prime}$ and $3^{\prime}$ terminal sequences derived from FeLV env gene, and an intracellular region harboring transmembrane (TM) and ankyrin (ANK)-repeats of the feline Notch2 gene. Both clones had short 23-amino-acid open reading frame (ORF), possibly derived from the FeLV env gene (Fig. 2A). A second ORF contained a sequence with a frame-shifted env sequence at its C-terminal, and this ORF possibly expresses viral Notch2 (v-Notch2) fusion protein (Fig. 2B). Other researchers have reported similar Notch2 transduction during experimental infection of cats with FeLV 61E, a cloned virus, and have isolated four clones of Notch2-FeLV from two cats [24]. Three recombinants had the same $5^{\prime}$ junctions as those seen in our clones; however, the $3^{\prime}$ junctions were dissimilar. The second ORF of the recombinant v-Notch2 protein is translated by using the internal ribosome entry site (IRES) activity within the TM region of Notch2 [14]. All variants isolated to date include the intracellular region of Notch2 with functional ANK repeats and two nuclear location signals (NLSs). Such truncated expression of Notch receptors can lead to the constitutive activation of Notch signaling [reviewed in 12]. Direct repeat sequences of the enhancer or the upstream of the enhancer (URE) [21] were not seen in the LTR of KeyN2-2.

We further analyzed activation of Notch signaling pathway by the v-Notch 2 protein using transient luciferase reporter assays. The predicted second ORF of clone KeyN2-2 was amplified by PCR using specific primers (5'-GAG GAT CCA TGG CGA AAC GAA AGC GTA A-3' (Fe-250S) and 5'-TTG AAT TCT TAC AGG TCT TCT TCA GAG ATC AGT TTC TGT TCG CTG GAA GTC ATG GTT GG-3' (Fe223R), tagged with Myc at the C-terminus and then cloned into the $\mathrm{pFU} \Delta \mathrm{ss}$ expression vector [1]. The v-Notch2 protein was transiently expressed in HEK293T cells using ScreenFect A (Wako, Osaka, Japan) as manufacturer's instructions (Fig. 3A). Co-transfection of our plasmid with pGa981-6 


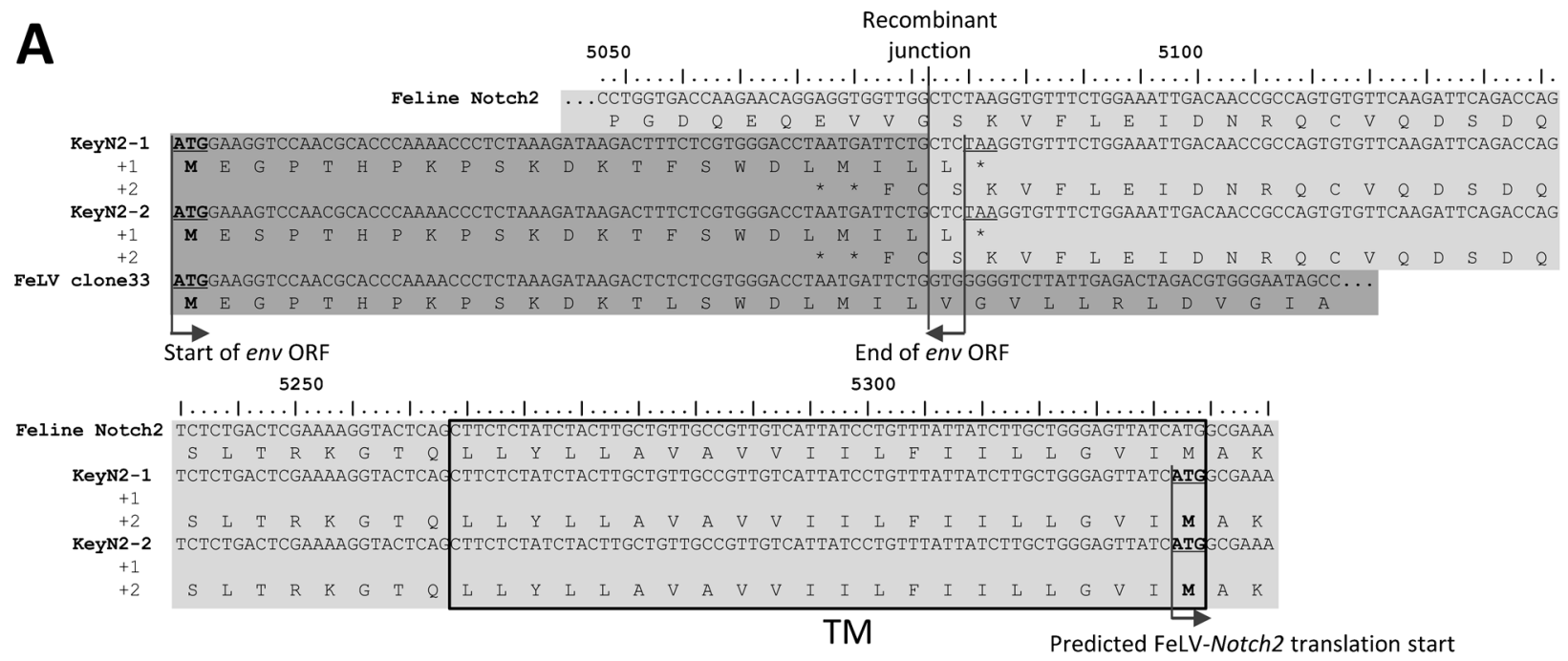

B

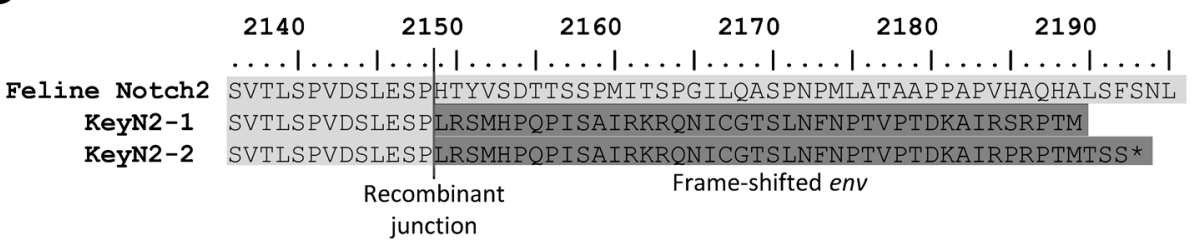

Fig. 2. The sequence alignment of Notch2-FeLV recombinant junctions flanking the $5^{\prime}(\mathrm{A})$ and $3^{\prime}$ (B) regions. Predicted start codons of the env gene and the recombinant Notch2 are underlined and in bold. FeLV clone 33 (GenBank accession no. AB060732) [22] was used as a prototype FeLV reference sequence. The reading frame of the 3' terminus of the env gene was frame-shifted (red). *Stop codon. TM; Notch2 transmembrane.

A

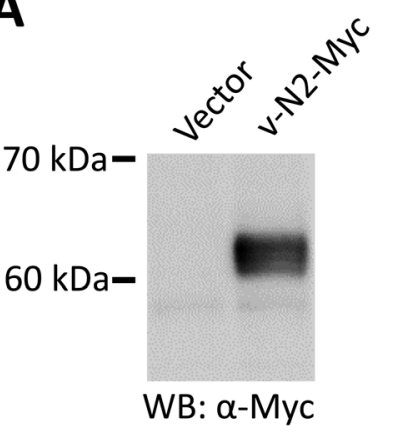

Actin
B

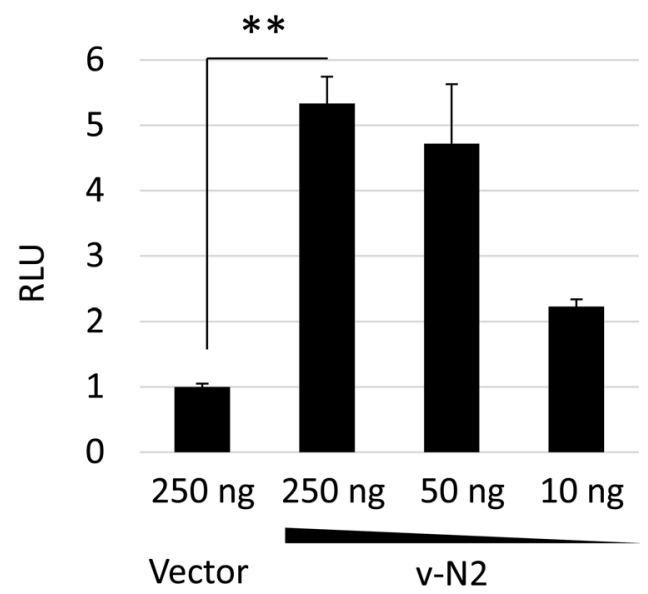

Fig. 3. Expression and activation of v-Notch2 protein. (A) Expression of Myc-tagged v-Notch2 proteins in transiently transfected HEK293T cells. HEK293T cells were transfected with pFU $\Delta \mathrm{ss}$ expression vector (vector) [1] or pFU $\Delta$ ss-KeyN2-Myc (v-N2-Myc). Cells were collected after $48 \mathrm{hr}$, and total cell lysates were subjected to Western blotting analysis using mouse anti-Myc (Wako, Osaka, Japan) or mouse anti- $\beta$-Actin antibody (Santa Cruz Biotechnology, Santa Cruz, CA, U.S.A.). (B) HEK293T cells in 24-well plate were co-transfected with pGa981-6 (50 $\mathrm{ng})$, phRL-CMV (5 $\mathrm{ng}$ ) and $\mathrm{v}-$ Notch2 expressing plasmids ( $\mathrm{v}-\mathrm{N} 2)$. Luciferase assay was performed in triplicate, and the relative luciferase activity was measured using Dual-Luciferase Reporter Assay System (Promega) at $48 \mathrm{hr}$ post transfection. The relative luciferase unit (RLU) is shown relative to the negative control (vector). Error bars denote the standard deviation (SD). ${ }^{* *} P<0.01$ using unpaired $t$-test. 
[13], a firefly luciferase reporter containing the RBP-JK binding promoter and phRL-CMV reference plasmid (Promega, Madison, WI, U.S.A.) that constitutively expresses renilla luciferase showed dose-dependent activation of the v-Notch2 protein (Fig. 3B).

Lymphoma and refractory hypercalcemia was observed in our cat. Hypercalcemia is commonly linked to malignancy in dogs and humans, especially in lymphoma [7, 23]. In most cases of feline lymphoma, elevation of the serum calcium concentration or parathyroid hormone-related peptide (PTHrP) is uncommon $[2,25]$. Recently, an association between bone metabolism and Notch signaling has been revealed; RANKL-induced association of Notch2 and Jagged1 in pre-osteoclasts can lead to the differentiation into osteoclasts and activates osteoclastgenesis in them through

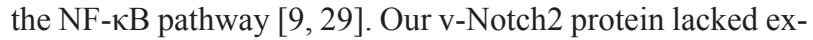
tracellular region of Notch2. Therefore, v-Notch2 likely possesses the potential to activate osteoclastgenesis independent of RANKL stimulation when overexpressed in osteoclast/ monocyte lineage cells.

Because of the recombination-prone property of gammaretroviruses, we observed numerous recombination events and various recombinant forms of FeLVs transducing cellular genes, including endogenous FeLV (enFeLV) [28] and ERV-DC [1]. The emergence of such recombinant viruses could alter the disease specificity, potential and outcome in FeLV-infected cats. Additionally, various numbers of protooncogenes, which function as a key regulator of proliferation and differentiation, have been historically identified in such recombinant gammaretroviruses. Although Notch2 has been recognized as tumor suppressor in some human tumors [17], transduction of Notch2 gene seems to be a feasible mechanisms for FeLV-induced lymphomagenesis. Finally, our report may provide a new insight into the relationship between the Notch signaling pathway and humoral hypercalcemia.

ACKNOWLEDGMENTS. The pGa981-6 reporter construct was provided by RIKEN BRC, which participates in the National Bio-Resources Project of the Ministry of Education, Culture, Sports, Science and Technology (MEXT), Japan. This study was supported by a grant from the MEXT, Japan (Grant\# 22380168).

\section{REFERENCES}

1. Anai, Y., Ochi, H., Watanabe, S., Nakagawa, S., Kawamura, M., Gojobori, T. and Nishigaki, K. 2012. Infectious endogenous retroviruses in cats and emergence of recombinant viruses. $J$. Virol. 86: 8634-8644. [Medline] [CrossRef]

2. Bolliger, A. P., Graham, P. A., Richard, V., Rosol, T. J., Nachreiner, R. F. and Refsal, K. R. 2002. Detection of parathyroid hormone - related protein in cats with humoral hypercalcemia of malignancy. Vet. Clin. Pathol. 31: 3-8. [Medline] [CrossRef]

3. Braun, M. J., Deininger, P. L. and Casey, J. W. 1985. Nucleotide sequence of a transduced myc gene from a defective feline leukemia provirus. J. Virol. 55: 177-183. [Medline]

4. Cotter, S. M. 1992. Feline leukemia virus: Pathophysiology, prevention, and treatment. Cancer Invest. 10: 173-181. [Medline]
[CrossRef]

5. Doggett, D. L., Drake, A. L., Hirsch, V., Rowe, M. E., Stallard, V. and Mullins, J. I. 1989. Structure, origin, and transforming activity of feline leukemia virus-myc recombinant provirus FTT. J. Virol. 63: 2108-2117. [Medline]

6. Dorn, C. R., Taylor, D. O. and Hibbard, H. H. 1967. Epizootiologic characteristics of canine and feline leukemia and lymphoma. Am. J. Vet. Res. 28: 993-1001. [Medline]

7. Elliott, J., Dobson, J. M., Dunn, J. K., Herrtage, M. E. and Jackson, K. F. 1991. Hypercalcaemia in the dog: A study of 40 cases. J. Small Anim. Pract. 32: 564-571. [CrossRef]

8. Ellisen, L. W., Bird, J., West, D. C., Soreng, A. L., Reynolds, T. C., Smith, S. D. and Sklar, J. 1991. TAN-1, the human homolog of the Drosophila Notch gene, is broken by chromosomal translocations in T lymphoblastic neoplasms. Cell 66: 649-661. [Medline] [CrossRef]

9. Fukushima, H., Nakao, A., Okamoto, F., Shin, M., Kajiya, H., Sakano, S., Bigas, A., Jimi, E. and Okabe, K. 2008. The association of Notch2 and NF-kappaB accelerates RANKL-induced osteoclastogenesis. Mol. Cell. Biol. 28: 6402-6412. [Medline] [CrossRef]

10. Fulton, R., Forrest, D., McFarlane, R., Onions, D. and Neil, J. C. 1987. Retroviral transduction of T-cell antigen receptor betachain and myc genes. Nature 326: 190-194. [Medline] [CrossRef]

11. Greenwald, I. 1994. Structure/function studies of lin-12/Notch proteins. Curr. Opin. Genet. Dev. 4: 556-562. [Medline] [CrossRef]

12. Kopan, R. and Ilagan, M. X. G. 2009. The canonical Notch signaling pathway: unfolding the activation mechanism. Cell 137: 216-233. [Medline] [CrossRef]

13. Kurooka, H., Kuroda, K. and Honjo, T. 1998. Roles of the ankyrin repeats and C-terminal region of the mouse notch 1 intracellular region. Nucl. Acids Res. 26: 5448-5455. [Medline] [CrossRef]

14. Lauring, A. S. and Overbaugh, J. 2000. Evidence that an IRES within the Notch2 Coding Region Can Direct Expression of a Nuclear Form of the Protein. Mol. Cell Biol. 6: 939-945. [Medline] [CrossRef]

15. Lee, S., Kumano, K., Nakazaki, K., Sanada, M., Matsumoto, A., Yamamoto, G., Nannya, Y., Suzuki, R., Ota, S., Ota, Y., Izutsu, K., Sakata-Yanagimoto, M., Hangaishi, A., Yagita, H., Fukayama, M., Seto, M., Kurokawa, M., Ogawa, S. and Chiba, S. 2009. Gain-of-function mutations and copy number increases of Notch2 in diffuse large B-cell lymphoma. Cancer Sci. 100: 920-926. [Medline] [CrossRef]

16. Levy, L. S., Gardner, M. B. and Casey, J. W. 1984. Isolation of a feline leukaemia provirus containing the oncogene $m y c$ from a feline lymphosarcoma. Nature 308: 853-856. [Medline] [CrossRef]

17. Lobry, C., Oh, P. and Aifantis, I. 2011. Oncogenic and tumor suppressor functions of Notch in cancer: it's NOTCH what you think. J. Exp. Med. 208: 1931-1935. [Medline] [CrossRef]

18. Mullins, J. I., Brody, D. S., Binari, R. C. Jr. and Cotter, S. M. 1984. Viral transduction of c-myc gene in naturally occurring feline leukaemias. Nature 308: 856-858. [Medline] [CrossRef]

19. Neil, J. C., Forrest, D., Doggett, D. L. and Mullins, J. I. 1987. The role of feline leukaemia virus in naturally occurring leukaemias. Cancer Surv. 6: 117-137. [Medline]

20. Neil, J. C., Hughes, D., McFarlane, R., Wilkie, N. M., Onions, D. E., Lees, G. and Jarrett, O. 1984. Transduction and rearrangement of the $m y c$ gene by feline leukaemia virus in naturally occurring T-cell leukaemias. Nature 308: 814-820. [Medline] 
[CrossRef]

21. Nishigaki, K., Okuda, M., Endo, Y., Watari, T., Tsujimoto, H. and Hasegawa, A. 1997. Structure and function of the long terminal repeats of feline leukemia viruses derived from naturally occurring acute myeloid leukemias in cats. J. Virol. 71: 9823-9827. [Medline]

22. Nishigaki, K., Hanson, C., Thompson, D., Yugawa, T., Hisasue, M., Tsujimoto, H. and Ruscetti, S. K. 2002. Analysis of the disease potential of a recombinant retrovirus containing Friend murine leukemia virus sequences and a unique long terminal repeat from feline leukemia virus. J. Virol. 76: 1527-1532. [Medline] [CrossRef]

23. Potts, J. T. 1996. Hyperparathyroidism and other hypercalcemic disorders. Adv. Intern. Med. 41: 165-212. [Medline]

24. Rohn, J. L., Lauring, A. S., Linenberger, M. L. and Overbaugh, J. 1996. Transduction of Notch2 in feline leukemia virus-induced thymic lymphoma. J. Virol. 70: 8071-8080. [Medline]

25. Savary, K. C., Price, G. S. and Vaden, S. L. 2000. Hypercalcemia in cats: a retrospective study of 71 cases (1991-1997). J. Vet. Intern. Med. 14: 184-189. [Medline]

26. Stewart, M. A., Forrest, D., McFarlane, R., Onions, D., Wilkie, N. and Neil, J. C. 1986. Conservation of the c-myc coding se- quence in transduced feline v-myc genes. Virology 154: 121-134. [Medline] [CrossRef]

27. Trøen, G., Wlodarska, I., Warsame, A., Hernández Llodrà, S., De Wolf-Peeters, C. and Delabie, J. 2008. NOTCH2 mutations in marginal zone lymphoma. Haematologica 93: 1107-1109. [Medline] [CrossRef]

28. Watanabe, S., Kawamura, M., Odahara, Y., Anai, Y., Ochi, H., Nakagawa, S., Endo, Y., Tsujimoto, H. and Nishigaki, K. 2013. Evolutionary dynamics of the feline leukemia virus: phylogenetic and structural diversity in the env gene. PLoS one 8: e61009. [Medline] [CrossRef]

29. Weber, J. M., Forsythe, S. R., Christianson, C. A., Frisch, B. J., Gigliotti, B. J., Jordan, C. T., Milner, L. A., Guzman, M. L. and Calvi, L. M. 2006. Parathyroid hormone stimulates expression of the Notch ligand Jagged1 in osteoblastic cells. Bone 39: 485-493. [Medline] [CrossRef]

30. Weng, A. P., Ferrando, A. A., Lee, W., Morris, J. P., Silverman, L. B., Sanchez-Irizarry, C., Blacklow, S. C., Look, A. T. and Aster, J. C. 2004. Activating mutations of NOTCH1 in human $\mathrm{T}$ cell acute lymphoblastic leukemia. Science 306: 269-271. [Medline] [CrossRef] 